\title{
PROGNOSTIC ASSESSMENT OF 1310 PATIENTS WITH NON-SMALL-CELL LUNG CANCER WHO UNDERWENT COMPLETE RESECTION FROM 1980 TO 1993
}

Kunihiko Inoue, $\mathrm{MD}^{\mathrm{a}}$

Masami Sato, MD,

Shigefumi Fujimura, MD

Akira Sakurada, MD ${ }^{a}$

Satomi Takahashi, $\mathrm{MD}^{\mathrm{b}}$

Katsuo Usuda, MD ${ }^{\mathrm{b}}$

Takashi Kondo, $\mathrm{MD}^{\mathrm{a}}$

Tatsuo Tanita, MD

Masashi Handa, MD

Yasuki Saito, $\mathrm{MD}^{\mathrm{c}}$

Motoyasu Sagawa, MD
Objective: The TNM staging system of lung cancer is widely used as a guide for estimating prognosis and selecting treatment modality. In 1997, the International Union Against Cancer and the American Joint Committee on Cancer have adopted a revised stage grouping for lung cancer. However, the validity of the new stage grouping has not been fully established. We investigated the prognoses of patients who had resection of non-small-cell lung cancer to confirm the validity of the revised classification. Methods: A total of 1310 patients with non-small-cell lung cancer underwent complete resection and pathologic staging of the disease in our hospitals from 1980 through 1993. A pulmonary resection was performed with a systematic nodal dissection. The survivals were calculated with the Kaplan-Meier method on the basis of overall deaths, and the survival curves were compared by $\log$ rank test. Results: There were significant differences in survival between patients with $\mathrm{T} 1 \mathrm{NO} \mathrm{M} 0$ and $\mathrm{T} 2 \mathrm{NO}$ M0 disease and between those with T1 N1 M0 and T2 N1 M0 disease. However, there was no significant difference between patients with T2 N0 M0 disease and those with T1 N1 M0 disease. No significant difference in survival was observed among patients with T2 N1 MO, T3 NO M0, and T3 N1 MO cancer. Patients with different invaded organs of $\mathrm{T3}$ subdivision (pleura, chest wall, pericardium, or diaphragm) had a different prognosis. There was no significant difference between patients with $\mathrm{T3}$ N2 M0 disease and those with stage IIIB disease. Conclusions: We supported most of the revision, such as dividing stage I, dividing stage II, and putting T3 NO MO to stage IB. Furthermore, we found some candidates for a subsequent revision, such as putting T3 N1 M0 to stage IIB, putting T2 N0 M0 and T1 N1 M0 together, regarding diaphragm invasion as T4, and putting T3 N2 M0 to stage IIIB. (J Thorac Cardiovase Surg 1998;116:407-11)
$T^{\text {he }}$ he TNM staging system of lung cancer is widely used as a guide for estimating prognosis and selecting treatment modality. ${ }^{1-3}$ Recently some

From the Department of Thoracic Surgery, Institute of Development, Aging and Cancer, Tohoku Universitya; the Department of Surgery, Sendai Kosei Hospital ${ }^{\text {b; }}$ and the Department of "Thoracic Surgery, National Sendai Hospital," Sendai, Japan.

Supported by grants of the Ministry of Education, Science, Sports, and Culture, Japan.

Received for publication Jan 2, 1998; revisions requested March 26, 1998; revisions received April 23, 1998; accepted for publication May 20, 1998.

Address for reprints: Kunihiko Inoue, MD, Department of Thoracic Surgery, Institute of Development, Aging and Cancer Tohoku University, Sendai, Japan.

Copyright (C 1998 by Mosby, Inc.

$0022-5223 / 98 \$ 5.00+0 \quad \mathbf{1 2 / 1 / 9 1 8 4 4}$ questions have arisen about whether the present TNM staging really reflects the exact prognosis. ${ }^{4}$ In 1997, the International Union Against Cancer (UICC) and the American Joint Committee on Cancer have adopted a revised stage grouping. ${ }^{5}$ However, the validity of the new stage grouping has not been fully established. In this report, we investigate the prognoses of 1310 patients with completely resected non-small-cell lung cancer on the basis of the pathologic TNM classification to confirm the validity of the revised classification and to analyze other prognostic factors.

\section{Patients and methods}

A total of 1310 patients with non-small-cell lung cancer underwent complete resection and pathologic staging of the disease in our hospitals from 1980 through 1993. In this period, chest computed tomography, brain computed 
Table I. The characteristics of the 1310 patients in this study

\begin{tabular}{lcc}
\hline Characteristic & No. of patients & Percentage \\
\hline Sex & & \\
Male & 968 & 73.9 \\
Female & 342 & 26.1 \\
Histologic type & & \\
SQ & 556 & 42.4 \\
AD & 645 & 49.3 \\
LA & 109 & 8.3 \\
T factor & & \\
T1 & 602 & 45.9 \\
T2 & 564 & 43.1 \\
T3 & 122 & 9.3 \\
T4 & 22 & 1.7 \\
N factor & & \\
N0 & 803 & 61.3 \\
N1 & 245 & 18.7 \\
N2 & 260 & 19.8 \\
N3 & 2 & 0.2 \\
Stage & & \\
Stage I & 752 & 57.5 \\
Stage II & 197 & 15.0 \\
Stage IIIA & 337 & 25.7 \\
Stage IIIB & 24 & 1.8
\end{tabular}

$S Q$, Squamous cell carcinoma; $A D$, adenocarcinoma; $L A$, large cell carcinoma.

${ }^{*}$ Age: 28 to 85 years (mean, 64.5 years).

tomography, abdominal ultrasonography, and bone scintigraphy were routinely performed before operation to evaluate distant metastasis. ${ }^{4} \mathrm{~A}$ randomized trial for postoperative adjuvant chemotherapy was conducted in this period, but the results revealed no survival advantage or disadvantage with our regimen (unpublished data). Induction therapy was not performed in this period especially for the patients who had been expecting a complete resection. A lobectomy or a pneumonectomy was performed with the dissection of hilar and mediastinal lymph nodes (systematic nodal dissection ${ }^{6}$ ). Lymph nodes were numbered according to lymph node mapping reportcd by Naruke and associates. ${ }^{7}$ The patients were classified on the basis of the pathologic TNM classification of the UICC. ${ }^{5}$ Histologic typing was determined according to the World Health Organization classification. ${ }^{8}$ The survivals were calculated with the Kaplan-Meier method on the basis of overall death including operative deaths, and the survival curves were compared by log rank test.

\section{Results}

Patients' characteristics and TNM distribution are shown in Tables I and II. Five-year survivals of patients with T1 N0 M0, T2 N0 M0, T1 N1 M0, and T2 N1 M0 diseases were $80 \%, 65 \%, 57 \%$, and $42 \%$, respectively (Fig. 1). There were significant differences in survival between patients with T1 N0 M0 and T2 N0 M0 diseases $(P=.001)$ and between patients with $\mathrm{T} 1 \mathrm{~N} 1 \mathrm{M} 0$ and $\mathrm{T} 2 \mathrm{~N} 1 \mathrm{M} 0$ diseases
Table II. The distribution of patients in the TNM subsets

\begin{tabular}{lcc}
\hline Stage (old) & TNM subset & No. of patients (\%) \\
\hline Stage I & T1 N0 M0 & $480(36.6)$ \\
\multirow{3}{*}{ Stage II } & T2 N0 M0 & $271(20.6)$ \\
& T1 N1 M0 & $57(4.4)$ \\
Stage IIIA & T2 N1 M0 & $141(10.8)$ \\
& T3 N0 M0 & $46(3.5)$ \\
& T3 N1 M0 & $39(3.0)$ \\
Ttage IIIB & T1 N2 M0 & $65(5.0)$ \\
& T2 N2 M0 & $150(11.4)$ \\
& T3 N2 M0 & $37(2.8)$ \\
& T4 N0 M0 & $6(0.5)$ \\
& T4 N1 M0 & $8(0.6)$ \\
& T4 N2 M0 & $8(0.6)$ \\
& T2 N3 M0 & $2(0.2)$ \\
\hline
\end{tabular}

$(P=.02)$. However, there was no significant difference between patients with $\mathrm{T} 2 \mathrm{~N} 0 \mathrm{M} 0$ and $\mathrm{T} 1 \mathrm{~N} 1$ M0 diseases.

Fig. 2 shows survival curves of T2 N1 M0, T3 N0 $\mathrm{M} 0$, and T3 N1 M0 diseases; there was no significant difference in survival among patients with T2 N1 M0 (5-year survival, 42\%), T3 N0 M0 (5-year survival, $34 \%$ ), and T3 N1 M0 (5-year survival, 38\%) diseases.

To estimate the contribution of invaded organ to the prognosis, we compared survival curves of patients with T3 N0-1 M0 disease according to the invaded organ (Fig. 3). Patients with T3 N0 M0 disease and patients with $\mathrm{T} 3 \mathrm{~N} 1 \mathrm{M} 0$ disease were united for the estimation because they had similar survival curves, whereas patients with T3 N2 M0 disease had significantly poorer prognoses. Patients with different invaded organs of T3 subdivision had different prognoses; pleura (5-year survival, 35\%), chest wall (5-year survival, 26\%), pericardium (5year survival, $43 \%$ ), and diaphragm (3-year survival, none).

Fig. 4 shows the survival curves of patients with T3 N2 M0 disease and patients with stage IIIB disease. The prognosis of patients with completely resected T3 N2 M0 disease (5-year survival, 11\%) was poorer than that of patients with completely resected stage IIIB disease (5-year survival, 36\%). There was no significant difference in survival between patients with T3 N2 M0 disease and those with stage IIIB disease.

\section{Discussion}

The TNM staging system of lung cancer was revised in $1997^{5,6,9}$ The staging system should be revised according to the prognosis of the patients 


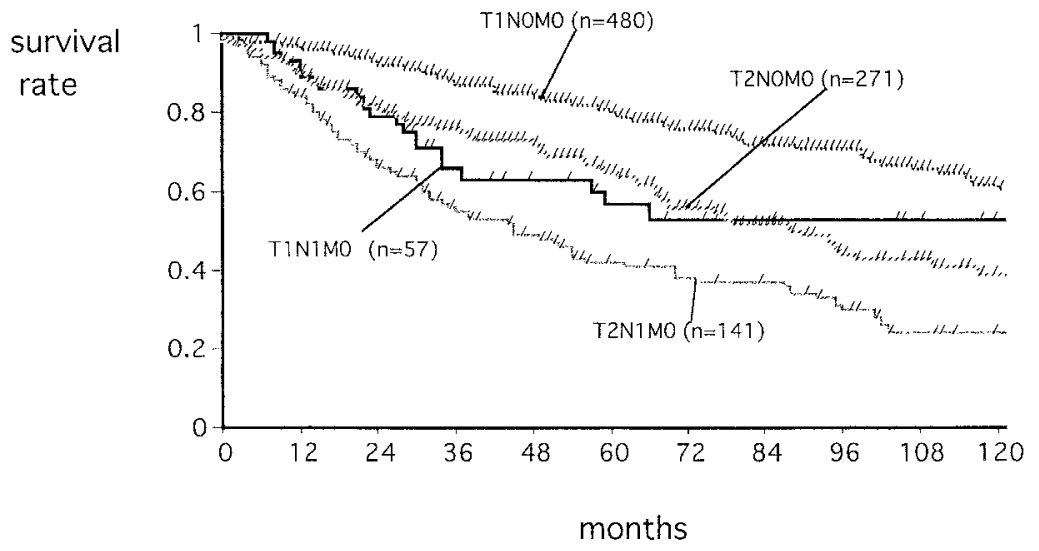

Fig. 1. The postoperative survival curves of patients with $\mathrm{T} 1 \mathrm{~N} 0 \mathrm{M} 0, \mathrm{~T} 2 \mathrm{~N} 0 \mathrm{M} 0, \mathrm{~T} 1 \mathrm{~N} 1 \mathrm{M} 0$, and $\mathrm{T} 2 \mathrm{~N} 1 \mathrm{M} 0$ diseases show that there are significant differences between the prognoses of patients with T1 N0 M0 and T2 N0 M0 diseases $(P=.001)$ and between those of patients with T1 N1 M0 and T2 N1 M0 diseases $(P=$ $.02)$.

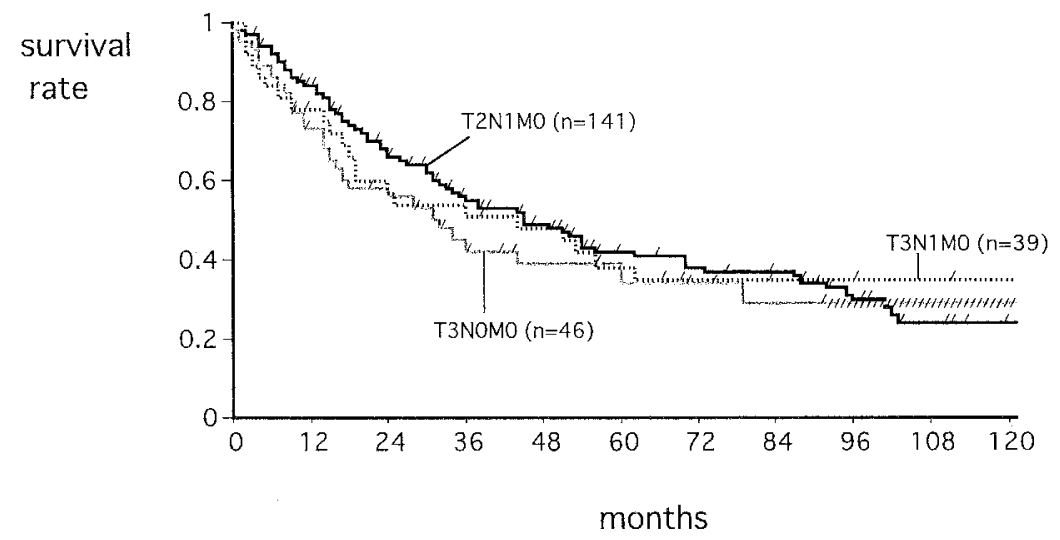

Fig. 2. The postoperative survival curves show that there are no significant differences in the survivals among of patients with T2 N1 M0, T3 N0 M0, and T3 N1 M0 diseases.

who have relatively homogeneous backgrounds. In this present study, with which we attempted to assess the validity of the revision, we limited the cases to 1980 through 1993 because preoperative examinations in our institute were similar in this period. ${ }^{4}$

In the revised TNM staging, stage $I$ is divided into stage IA and stage IB. Stage II is also divided into stage IIA and stage IIB. Our results supported these divisions, because there were statistically significant differences between the prognoses of patients with T1 N0 M0 and T2 N0 M0 diseases and between those of patients with $\mathrm{T} 1 \mathrm{~N} 1 \mathrm{M} 0$ and $\mathrm{T} 2 \mathrm{~N} 1 \mathrm{M} 0$ diseases. However, there was no difference between patients with $\mathrm{T} 2 \mathrm{NO} \mathrm{M} 0$ and $\mathrm{T} 1 \mathrm{~N} 1 \mathrm{M} 0$ diseases. Mountain ${ }^{9}$ also reported that the survivals of patients with T2 N0 M0 and T1 N1 M0 diseases were
$57 \%$ and 55\%. T2 N0 M0 subgroup and T1 N1 M0 subgroup may be included in the same group (it does not mean T1 N1 M0 should be included in stage I).

T3 N0 M0 subgroup is included in stage IIB in the revised TNM staging. Because there was no difference between the prognosis of patients with T2 N1 M0 and T3 N0 M0 diseases, our results supported the revision. On the other hand, T3 N1 Mo is still controversial. Some investigators reported that patients with T3 N1 M0 diseases and patients with $\mathrm{T} 3 \mathrm{~N} 2 \mathrm{M} 0$ diseases had a similar prognosis. ${ }^{10}$ However, others including $\mathrm{us}^{2,11,12}$ reported that patients with T3 N1 M0 diseases had a more preferable prognosis than patients with T3 N2 M0 diseases. Mediastinal nodal involvement is 


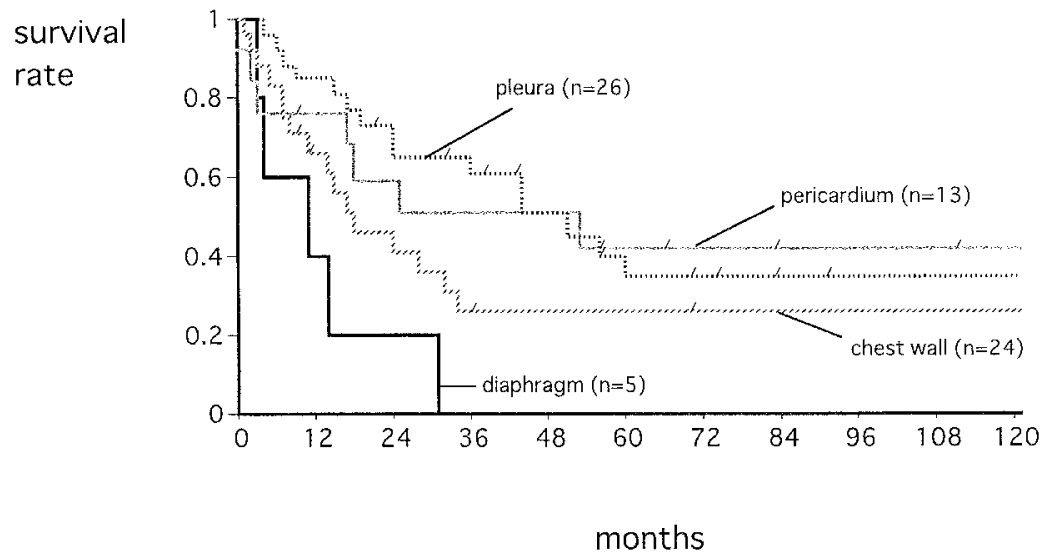

Fig. 3. The postoperative survival curves of patients with $\mathrm{T} 3 \mathrm{~N} 0-1 \mathrm{M} 0$ diseases show that, according to the invaded organ, patients with resected T3 tumors invading the diaphragm have a poor prognosis.

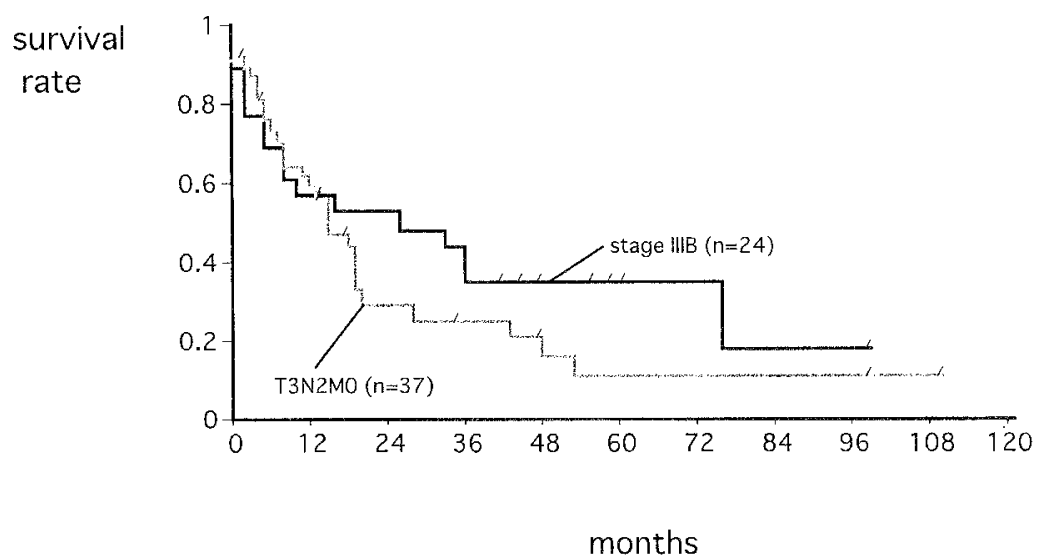

Fig. 4. The postoperative survival curves of patients with $\mathrm{T} 3 \mathrm{~N} 2 \mathrm{M} 0$ and stage IIIB diseases show that there is no significant difference between the prognoses.

one of the most important prognostic factors and strongly influences survival in patients with lung cancer. Although T3 N1 M0 may be another candidate of subgroup in stage IIB, further studies are required to find correct grouping.

Some investigators ${ }^{11}$ pointed out that T3 factors were heterogeneous. For the comparison of the prognosis according to the invaded organ, patients with $\mathrm{N} 2$ diseases were excluded to eliminate the influence of $\mathrm{N}$ factor. ${ }^{13}$ In our patients with lung cancer invading diaphragm, there were no 3-year survivors. There has been only one report concerning the prognosis after the resection of the tumors invading the diaphragm, ${ }^{11,14}$ Weksler and associates $^{14}$ reported 8 cases with resected T3 tumors invading the diaphragm in which there were no 4-year survivors, although 3 of the patients died of other causes. Some cancer cells in the lymph on the diaphragm flow to the abdominal lymph system, which is impossible to dissect. Tumors invading the diaphragm may be a candidate of T4 subgroup; however, the examination of a large number of cases, such as a multicenter study, is required.

Patients with T3 N2 M0 diseases who have undergone complete resection had poor prognoses. ${ }^{15}$ There was no difference between the survival of patients with $\mathrm{T} 3 \mathrm{~N} 2 \mathrm{M} 0$ diseases and that of patients with stage IIIB disease. One of the reasons for the similarity is that most of our patients with stage IIIB disease were selected cases (ie, only 2 patients had N3 disease and $64 \%$ of patients in the T4 classification had N0-1 diseases). However, it still suggests 
that T3 N2 M0 diseases are extensively advanced and that the T3 N2 M0 subgroup may be included in stage IIIB.

Most of our results supported the revision of the staging system proposed by the UICC and the AJCC in 1997. However, on the basis of our results, we present here some candidates for a subsequent revision. We ask for the assessment of our proposal by other investigators. After thorough discussions based on various results from different institutions, the next revision of the TNM staging would reflect the prognosis more precisely., 6

We thank Ms. Mitsuko Hasegawa and Ms. Kayoko Aihara for their assistance.

\section{REFERENCES}

1. Mountain $\mathrm{CF}$. A new international staging system for lung cancer. Chest 1986;89:225S-33S.

2. Naruke T, Goya T, Tsuchiya R, Suemasu K. Prognosis and survival in resected lung carcinoma based on the new international staging system. J Thorac Cardiovasc Surg 1988;96: 440-7.

3. Feld R, Abratt R, Graziano S, Jassen J, Lacquet L, Ninane V, et al. Consensus report: pretreatment minimal staging and prognostic factors for non-small cell lung cancer. Lung Cancer 1997; 17:S3-10.

4. Ginsberg R, Cox J, Green M, Bulzebruck H, Grunenwald D, Harper P, et al. Consensus report: Staging Classification Committee. Lung Cancer 1997;17:S11-3.
5. International Union Against Cancer. TNM classification of malignant tumors. 5th ed. New York: Wiley-Liss; 1997. p.93-7.

6. Goldstraw P. Meeting summary: report on the international workshop on intrathoracic staging. London, October 1996. Lung Cancer 1997;18:107-11.

7. Naruke T, Suemasu K, Ishikawa S. Lymph node mapping and curability of various levels of metastases in resected lung cancer. J Thorac Cardiovasc Surg 1978;76:832-9.

8. World Health Organization. Histological typing of lung tumors. 2nd ed. Geneva: WHO; 1981.

9. Mountain CF. Revisions in the international system for staging lung cancer. Chest 1997;111:1710-7.

10. Sabanathan S, Richardson J, Mearns AJ, Goulden C. Results of surgical treatment of stage III lung cancer. Eur J Cardiothorac Surg 1994;8:183-7.

11. Detterbeck FC, Socinski MA. IIB or not IIB: the current question in staging non-small cell lung cancer. Chest 1997; 112:229-34.

12. Ichinose Y, Yano T, Asoh H, Yokoyama H, Yoshino I, Katsuda Y. Prognostic factors obtained by a pathologic examination in completely resected non-small-cell lung cancer. J Thorac Cardiovasc Surg 1995;110:601-5.

13. Martini N, Yellin A, Ginsberg RJ, Bains MS, Burt ME, McCormack PM, et al. Management of non-small cell lung cancer with direct mediastinal involvement. Ann Thorac Surg 1994;58:1447-51.

14. Weksler B, Bains M, Burt M, Downey R, Martini N, Rusch $\mathrm{V}$, et al. Resection of lung cancer invading the diaphragm. J Thorac Cardiovasc Surg 1997;114:500-1.

15. Cangemi V, Volpino P, D'Andrea N, Chiarotti F, Tomassini R, Piat G. Results of surgical treatment of stage IIIA non-small cell lung cancer. Eur J Cardiothorac Surg 1995;9: $352-9$.

\section{Bound volumes available to subscribers}

Bound volumes of The Journal of Thoracic and Cardiovascular Surgery are available to subscribers (only) for the 1998 issues from the Publisher, at a cost of $\$ 122.00$ for domestic, $\$ 151.94$ for Canadian, and $\$ 142.00$ for international subscribers for Vol 115 (January-June) and Vol 116 (July-December). Shipping charges are included. Each bound volume contains a subject and author index and all advertising is removed. Copies are shipped within 60 days after publication of the last issue of the volume. The binding is durable buckram with the Journal name, volume number, and year stamped in gold on the spine. Payment must accompany all orders. Contact Mosby, Inc, Subscription Services, 11830 Westline Industrial Drive, St Louis, Missouri 63146-3318, USA; phone $800-453-4351$ or $314-453-4351$.

Subscriptions must be in force to qualify. Bound volumes are not available in place of a regular Journal subscription. 